\title{
The apolipoprotein A-I mimetic peptide, ETC-642, reduces chronic vascular inflammation in the rabbit
}

\author{
Belinda A Di Bartolo', Laura Z Vanags ${ }^{2}$, Joanne TM Tan², Shisan Bao ${ }^{3}$, Kerry-Anne Rye ${ }^{1,4,5}$, Philip J Barter ${ }^{1,4}$ and
} Christina A Bursill ${ }^{2,4^{*}}$

\begin{abstract}
Background: High-density lipoproteins (HDL) and their main apolipoprotein, apoA-l, exhibit anti-inflammatory properties. The development of peptides that mimic HDL apolipoproteins offers a promising strategy to reduce inflammatory disease. This study aimed to compare the anti-inflammatory effects of ETC-642, an apoA-I mimetic peptide, with that of discoidal reconstituted $\mathrm{HDL}$ (rHDL), consisting of full-length apoA-I complexed with phosphatidylcholine, in rabbits with chronic vascular inflammation.

Results: New Zealand White rabbits ( $n=10$ /group) were placed on chow supplemented with $0.2 \%(\mathrm{~W} / \mathrm{w})$ cholesterol for 6-weeks. The animals received two infusions of saline, rHDL (8 mg/kg apoA-l) or ETC-642 (30 mg/kg peptide) on the third and fifth days of the final week. The infusions of rHDL and ETC-642 were able to significantly reduce cholesterol-induced expression of intracellular cell adhesion molecule-1 (ICAM-1) and vascular cell adhesion molecule-1 (VCAM-1) in the thoracic aorta $(p<0.05)$. When isolated rabbit HDL was pre-incubated with human coronary artery endothelial cells (HCAECs), prior to stimulation with TNF- $\alpha$, it was found that HDL from ETC-642 treated rabbits were more effective at inhibiting the TNF- $\alpha$-induced increase in ICAM-1, VCAM-1 and p65 than HDL isolated from saline treated rabbits $(p<0.05)$. There were, however, no changes in HDL lipid composition between treatment groups.
\end{abstract}

Conclusions: Infusion of ETC-642 causes anti-inflammatory effects that are comparable to rHDL in an animal model of chronic vascular inflammation and highlights that apoA-I mimetic peptides present a viable strategy for the treatment of inflammatory disease.

Keywords: High-density lipoproteins, apolipoproteinA-I, apolipoproteinA-I mimetic peptides, vascular inflammation, rabbits, intracellular cell adhesion molecule-1 (ICAM-1) and vascular cell adhesion molecule-1 (VCAM-1)

\section{Background}

An increase in the endothelial cell expression of adhesion molecules such as vascular cell adhesion molecule1 (VCAM-1) and intercellular adhesion molecule-1 (ICAM-1) is characteristic of the initial inflammatory response triggered by endothelial damage or dysfunction [1]. Elevated expression of adhesion molecules promotes the recruitment and trans-endothelial migration of

\footnotetext{
* Correspondence: bursillc@hri.org.au

Immunobiology Unit, Heart Research Institute, 7 Eliza St, Newtown, NSW, 2042, Australia

Full list of author information is available at the end of the article
}

circulating monocytes into the artery wall, eventually leading to the development of atherosclerosis [1].

The anti-inflammatory properties of high-density lipoproteins (HDL) are well established [2]. In vitro studies have demonstrated that reconstituted (rHDL), containing apolipoprotein (apo) A-I (the main apolipoprotein constituent of HDL) complexed with phospholipids, inhibit the expression of VCAM-1 and ICAM-1 in human umbilical vein endothelial cells [3-6]. Consistent with this, in vivo studies in rabbits also show that lipid free apoA-I and rHDL reduce the expression of arterial VCAM-1 and ICAM-1 in the peri-arterial cuff model of acute inflammation $[3,7,8]$. Due to their potent anti-

\section{Ciomed Central}


inflammatory properties, both HDL and apoA-I have immense therapeutic potential, but despite this there is currently no translated use to clinic.

The limiting factor in the therapeutic usefulness of apoA-I is its relatively large size of 243 amino acids, thereby making its synthesis difficult. This has lead to the development of apoA-I mimetic peptides that are much shorter in length (18-22 peptides) and able to be readily synthesized on a large scale, but still exhibit the same beneficial properties as HDL and full-length apoAI. For example, infusions of mimetic peptides reduce atherosclerotic lesion size, improve endothelial dysfunction and also inhibit VCAM-1 and ICAM-1 expression in vitro and in vivo [9-13]. The apoA-I mimetic peptide used in our study, ETC-642, consists of a 22-amino acid synthetic amphipathic peptide complexed with sphingomyelin and 1,2-dipalmitoyl-sn-glycero-3-phosphocholine (DPPC) $[14,15]$. Recent studies have found that ETC642 is as effective as rHDL at suppressing acute inflammation in the rabbit peri-arterial collar model [16]. The anti-inflammatory effects of ETC-642 on chronic inflammation are, however, currently unknown.

Accordingly, this study has investigated the effect of ETC-642 on low-grade chronic vascular inflammation, in cholesterol-fed New Zealand White (NZW) rabbits $[17,18]$. We find that ETC-642 reduced the expression of VCAM-1 and ICAM-1 in the rabbit thoracic aorta to a similar extent as rHDL containing full-length apoA-I. These studies highlight the efficacy and therapeutic potential of mimetic peptides in the treatment of inflammation and cardiovascular disease.

\section{Results}

\section{Effects of the dietary intervention on plasma lipids}

The concentrations of plasma total cholesterol, HDL cholesterol and non-HDL are presented in Table 1. Consumption of a chow diet supplemented with $0.2 \%$ cholesterol for 6 weeks significantly increased total cholesterol concentrations ( $\sim 3$ fold) in all treatment groups $(\mathrm{p}<0.01)$. At sacrifice, there were no differences in plasma total cholesterol between the control animals and those receiving infusions of rHDL or ETC-642.
HDL cholesterol levels were not altered after six weeks of cholesterol feeding. Treatment with rHDL or ETC642 did not change HDL cholesterol levels, compared to saline infused rabbits, at the time of sacrifice.

Non-HDL cholesterol levels were significantly increased $(\mathrm{p}<0.05)$ with cholesterol feeding in rabbits injected with saline (22-fold), rHDL (9-fold) or ETC-642 (8.5 fold) ( $p<0.05$ for all). However, at the time of sacrifice there were no significant differences in nonHDL cholesterol concentrations between treatment groups.

\section{Effect of $r H D L$ and ETC-642 on chronic vascular inflammation}

The ability of rHDL and ETC-642 to reduce cholesterolinduced inflammation in the thoracic aorta was determined by measuring endothelial ICAM-1 and VCAM-1 expression (Figure 1). After six weeks of cholesterol feeding endothelial ICAM-1 expression was at readily detectable levels in rabbits infused with saline. In rabbits infused with rHDL, ICAM-1 expression was reduced by $58 \%(\mathrm{p}<0.05)$. The ETC-642 infusions were as effective as $\mathrm{rHDL}$ and reduced endothelial ICAM-1 expression by $53 \%(\mathrm{p}<0.05)$. Endothelial VCAM-1 expression was increased to detectable levels following 6 weeks of cholesterol feeding. Two infusions of rHDL or ETC-642 in the final week of cholesterol feeding were found to reduce VCAM-1 by $73 \%$ and $76 \%$ respectively $(\mathrm{p}<0.05)$.

After six weeks of cholesterol feeding there were no signs of fatty streak formation and therefore macrophages were not detected in the immuno-histochemically stained thoracic aortic sections.

\section{Effect of ETC-642 on the anti-inflammatory properties and composition of rabbit HDL}

HDL were isolated from the rabbits that were infused with saline, rHDL and ETC-642 and assessed for their ability to inhibit TNF- $\alpha$-induced expression of ICAM-1 and VCAM-1 in HCAECs (Figure 2). As expected, stimulation of HCAECs with TNF- $\alpha$ increased ICAM-1 (17.2 fold) and VCAM-1 (50.6 fold) mRNA levels, compared to un-stimulated control cells $(\mathrm{p}<0.001)$. When the cells were pre-incubated for 24 hrs with rHDL, the

Table 1 Effects of saline, rHDL and ETC-642 infusions on plasma lipid levels in NZW rabbits

\begin{tabular}{|c|c|c|c|c|c|c|}
\hline & \multicolumn{3}{|c|}{ BASELINE } & \multicolumn{3}{|c|}{ TIME OF SACRIFICE } \\
\hline & $\begin{array}{c}\mathrm{TC} \\
(\mathrm{mM} / \mathrm{L})\end{array}$ & $\begin{array}{l}\text { HDL-C } \\
(\mathrm{mM} / \mathrm{L})\end{array}$ & $\begin{array}{c}\text { Non HDL-C } \\
(\mathrm{mM} / \mathrm{L})\end{array}$ & $\begin{array}{c}\mathrm{TC} \\
(\mathrm{mM} / \mathrm{L})\end{array}$ & $\begin{array}{l}\text { HDL-C } \\
(\mathrm{mM} / \mathrm{L})\end{array}$ & $\begin{array}{c}\text { Non HDL-C } \\
(\mathrm{mM} / \mathrm{L})\end{array}$ \\
\hline SALINE & $0.86 \pm 0.07$ & $0.77 \pm 0.09$ & $0.09 \pm 0.07$ & $2.64 \pm 0.29^{*}$ & $0.65 \pm 0.03$ & $1.99 \pm 0.28^{*}$ \\
\hline rHDL & $0.84 \pm 0.06$ & $0.63 \pm 0.06$ & $0.21 \pm 0.06$ & $2.53 \pm 0.49^{*}$ & $0.66 \pm 0.06$ & $1.87 \pm 0.46^{*}$ \\
\hline ETC-642 & $0.99 \pm 0.05$ & $0.73 \pm 0.04$ & $0.26 \pm 0.06$ & $2.87 \pm 0.27^{*}$ & $0.61 \pm 0.05$ & $2.25 \pm 0.26^{*}$ \\
\hline
\end{tabular}

NZW rabbits ( $n=10 /$ group) were maintained on a diet of chow supplemented with $0.2 \%$ (w/w) cholesterol for 6 weeks On days 3 and 5 of the last week of dietary supplementation the animals received two infusions of saline, rHDL ( $8 \mathrm{mg} / \mathrm{kg}$ apoA-I) or ETC-642 (30 mg/kg peptide). Blood samples were collected at baseline and at sacrifice and plasma lipid levels were measured as described in "Materials and Methods". Results are expressed as mean \pm SEM. * $p<0.05$ compared to baseline. 


\section{Panel A}

ICAM-1

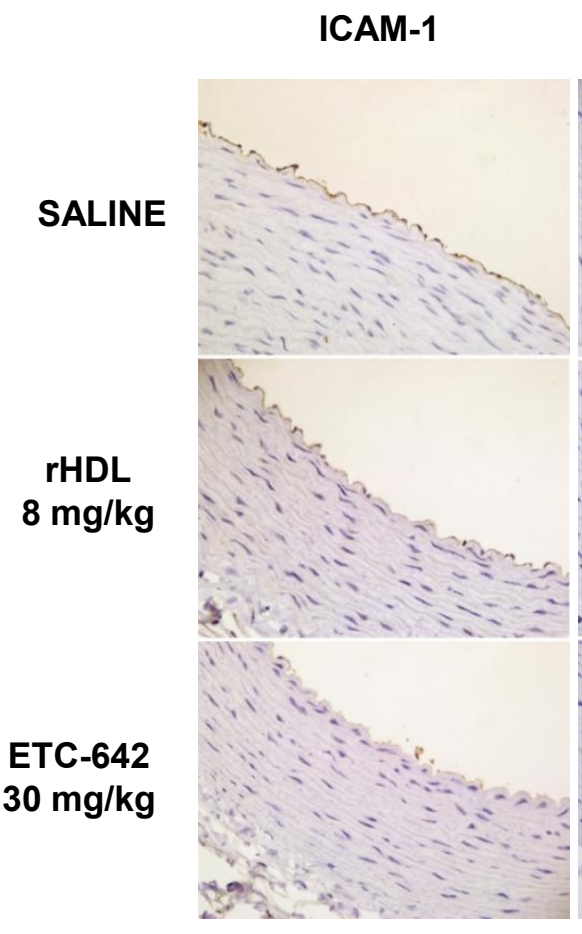

VCAM-1

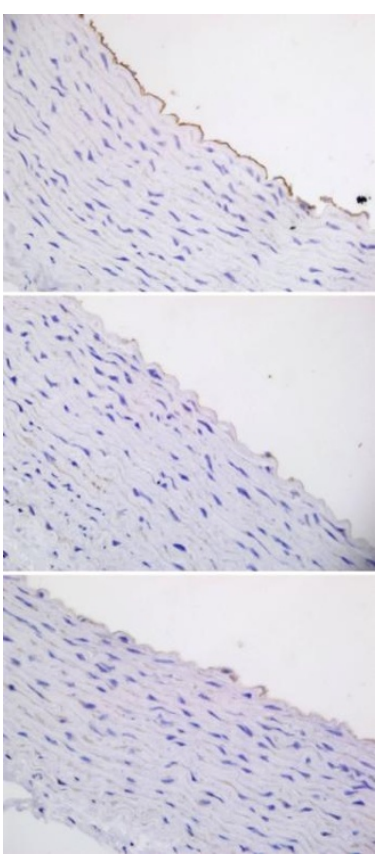

Panel B

ICAM-1

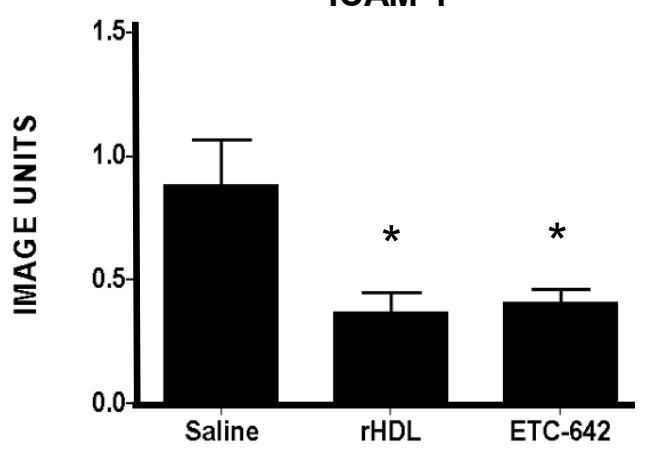

VCAM-1

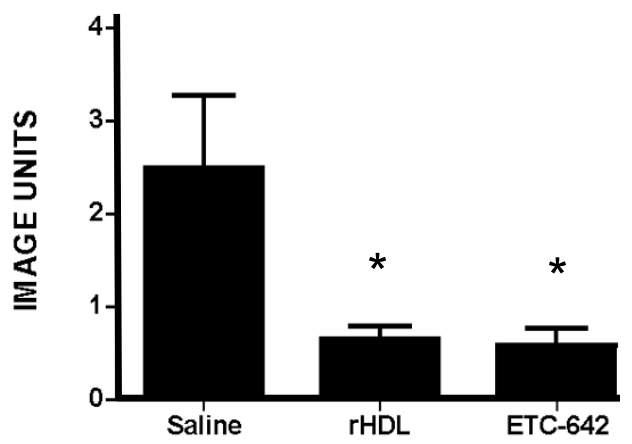

Figure 1 ETC-642 reduces endothelial adhesion molecule expression. Panel A: Immunohistochemical staining for ICAM-1 and VCAM-1 in representative thoracic aortic sections from cholesterol-fed NZW rabbits $(n=10$ animals/group) infused with either saline, rHDL (8 mg/kg apoAI) or ETC-642 (30 mg/kg peptide). Panel B: Endothelial expression of ICAM-1 and VCAM-1 were quantified as described in "Materials and Methods". Results are expressed as mean \pm SEM. ${ }^{*} p<0.05$ and ${ }^{* *} p<0.01$, compared to saline-infused animals.

TNF- $\alpha$-mediated increase in ICAM-1 and VCAM-1 mRNA levels was reduced by $35.5 \pm 19.4 \%(\mathrm{p}<0.05)$ and $73.8 \pm 8.4 \%(\mathrm{p}<0.001)$, respectively. We found that pre-incubation of cells with HDL from ETC-642 injected rabbits, caused reductions in TNF- $\alpha$-induced ICAM-1 (17.4 $\pm 3.0 \%)$ and VCAM-1 $(27.1 \pm 15.0 \%)$ mRNA levels $(\mathrm{p}<0.05)$. HCAECs incubated with HDL isolated from rabbits injected with saline and $\mathrm{rHDL}$ also expressed lower levels of ICAM-1 and VCAM-1 mRNA, compared to TNF- $\alpha$ stimulated controls, but these reductions did not reach statistical significance.

Changes in the mRNA levels of p65, the active subunit of NF- $\kappa \mathrm{B}$, were also measured, as it is a known regulator of ICAM-1 and VCAM-1 expression. Stimulation of HCAECs with TNF- $\alpha$ increased p65 mRNA levels $(1.5$ fold), compared to un-stimulated control cells ( $\mathrm{p}<$ $0.01)$. When cells were pre-incubated for $24 \mathrm{hrs}$ with rHDL, the TNF- $\alpha$-mediated increase in p65 mRNA levels was reduced by $36.0 \pm 13.4 \%(\mathrm{p}<0.05)$. We found that pre-incubation of cells with HDL from rabbits injected with saline and ETC-642 caused reduced TNF- $\alpha$-induced p 65 mRNA levels, by $21.4 \pm$ $10.8 \%$ and $31.0 \pm 4.3 \%$ respectively $(\mathrm{p}<0.05)$. Pre-incubation with HDL from the rabbits that received rHDL did not inhibit p65 mRNA levels.

Infusion of rHDL or ETC-642 did not significantly affect the composition of HDL. The relative concentrations of phospholipid, unesterified cholesterol, cholesterol ester and triglyceride were not statistically different from what was observed for HDL isolated from rabbits infused with saline (Table 2).

\section{Discussion}

The development of apoA-I mimetic peptides has provided much therapeutic promise for the treatment of inflammatory and cardiovascular diseases. ETC-642 is a 22 amino acid peptide that mimics the structure of the amphipathic $\alpha$-helices of apoA-I when combined with lipids. We therefore compared its ability to inhibit chronic vascular inflammation in cholesterol-fed rabbits, 


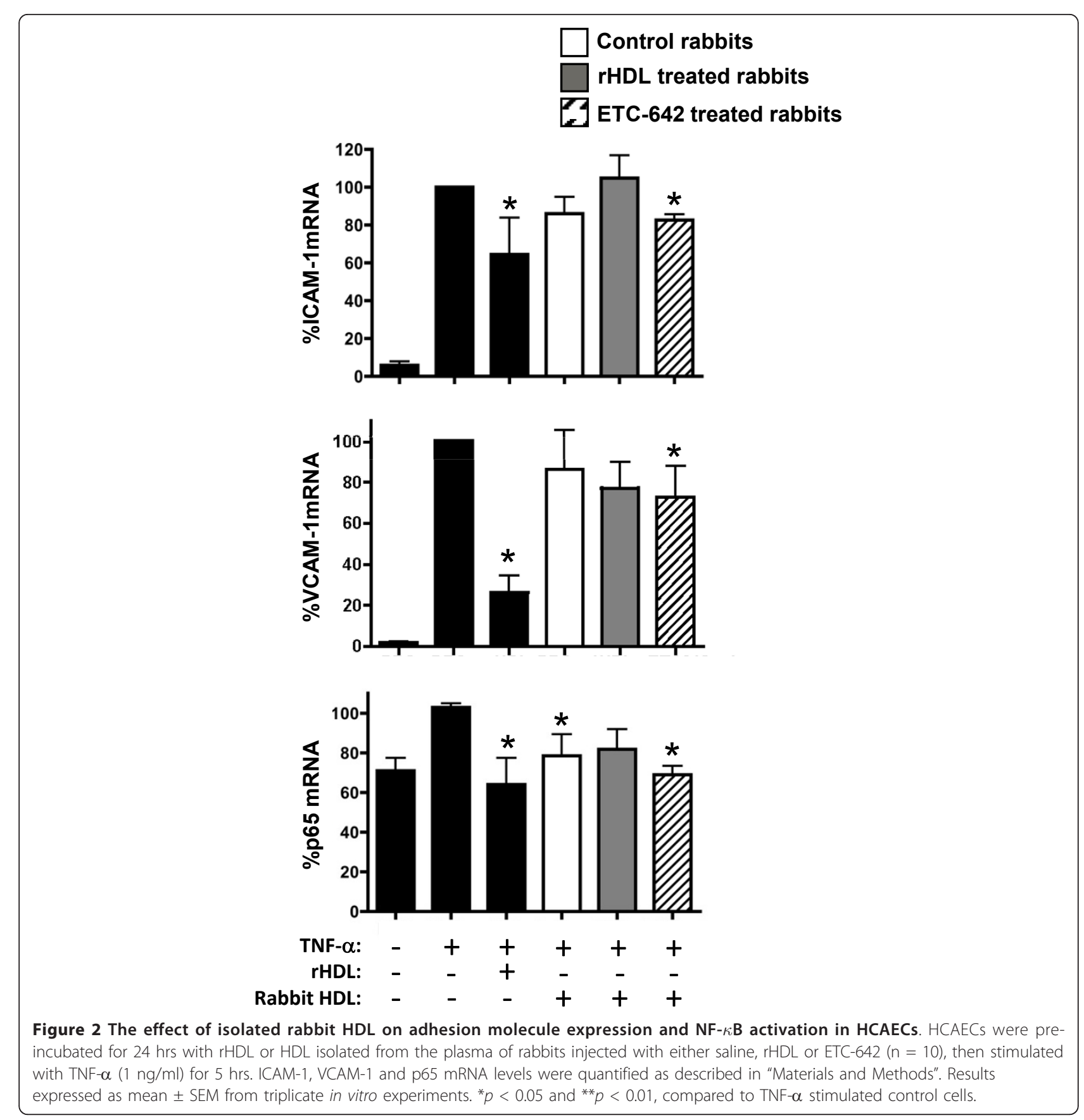

with that of rHDL (containing apoA-I and PLPC). We find, for the first time, that the mimetic peptide ETC642 inhibits adhesion molecule expression in this model. Furthermore, HDL isolated from rabbits injected with ETC-642 displays more potent anti-inflammatory properties than HDL isolated from rabbits injected with saline or rHDL.

Increased expression of adhesion molecules VCAM-1 and ICAM-1, represent the earliest vasculature alteration following the initiation of an atherogenic diet
$[17,18]$. Using a cholesterol-fed rabbit model, vascular inflammation develops gradually via a process that is somewhat comparable to early human lesion development [17]. In this model we have demonstrated that infusions of rHDL were able to significantly attenuate cholesterol-induced aortic expression of VCAM-1 and ICAM-1. These findings support the numerous in vitro studies that demonstrate the anti-inflammatory properties of rHDL and in vivo studies showing that rHDL and apoA-I inhibit acute vascular inflammation $[3,6,13,19]$. 
Table 2 Effects of saline, rHDL and ETC-642 infusions on HDL composition

\begin{tabular}{ll}
\hline Infusion & $\begin{array}{l}\text { Stoichiometry } \\
\mathrm{PL}^{\mathrm{a}} / \mathbf{U C} / \mathrm{CE} / \mathrm{TG} / \text { Protein } \\
(\mathbf{m o l} / \mathbf{m o l})\end{array}$ \\
\hline Saline & $27.0 \pm 6.8 / 10.5 \pm 1.0 / 24.0 \pm 1.3 / 1.3 \pm 0.2 / 1.0$ \\
rHDL & $33.5 \pm 6.6 / 7.9 \pm 0.9 / 21.8 \pm 1.1 / 1.8 \pm 0.4 / 1.0$ \\
ETC-642 & $32.5 \pm 10.2 / 10.8 \pm 1.0 / 22.1 \pm 2.0 / 1.4 \pm 0.3 / 1.0$ \\
\hline
\end{tabular}

NZW rabbits ( $n=10 /$ group) were maintained on a diet of chow supplemented with $0.2 \%(\mathrm{w} / \mathrm{w})$ cholesterol for 6 weeks. On days 3 and 5 of the last week of dietary supplementation the animals received two infusions of saline, rHDL (8 mg/kg apoA-I) or ETC-642 (30 mg/kg peptide). Blood was collected at sacrifice and $\mathrm{HDL}$ were isolated and their composition

determined as described in "Materials and Methods". Results are expressed as mean \pm SEM.

Furthermore, this study shows for the first time that the mimetic peptide ETC-642 can inhibit adhesion molecule expression in a model of chronic vascular inflammation. Our findings are also consistent with previous studies that have used ETC-642 and shown that it inhibits the development of similar inflammatory pathologies such as acute inflammation in the carotid artery in the rabbit peri-arterial collar model [16], cholesterol-induced aortic valve stenosis $[20]$ and atherosclerosis in apoE $^{-1-}$ mice [21].

The beneficial cardio-protective properties of HDL have been attributed to their ability to efflux cholesterol from cells, including endothelial cells [22,23]. Several studies have demonstrated that apoA-I mimetic peptides are also able to stimulate cholesterol efflux [13,24]. For example, infusions of ETC-642 transiently elevate cholesterol levels in rats and humans $[20,25]$, indicating enhanced mobilization of cell cholesterol into the plasma. Enhanced cholesterol efflux may provide a mechanism for the anti-inflammatory effects of ETC642 , as has been demonstrated by other mimetic peptides [13]. In the current study, however, we found that ETC-642 had no effect on plasma total cholesterol or HDL cholesterol concentrations at the time of sacrifice. The reason for this is likely to be that the final ETC-642 injection was 48 hours prior to sacrifice. As the cholesterol elevating properties of ETC-642 occur within 45 minutes after infusion [20], the lack of change at $48 \mathrm{~h}$ post-infusion is therefore to be expected [16]. This may also explain why HDL composition did not change following rHDL and ETC-642 infusions and confirms our recent work, which showed that injection of lipid free apoA-I and rHDL increased HDL phospholipid, unesterified cholesterol and cholesterol ester levels at $5 \mathrm{~min}$ utes, but not at $6 \mathrm{~h}$ after infusion [26].

Despite the lack of apparent compositional change in rabbit HDL between treatment groups, the HDL from rabbits infused with ETC-642 appeared to exert more potent anti-inflammatory effects ex vivo in HCAECs than the HDL from rabbits injected with saline or rHDL. Recent proteomic studies have identified multiple proteins that co-isolate with human HDL $[27,28]$, including for example antioxidants, protease inhibitors and growth factors. These HDL-associated proteins are likely to impart some of the beneficial physiological effects of HDL [27]. Changes in the presence of these HDL-associated proteins are also likely to alter HDL function. It is possible that whilst the ETC-642 infusions did not significantly alter the relative amounts of phospholipids, unesterified cholesterol, esterified cholesterol or triglycerides, it may have changed the protein composition of the rabbit HDL in a way that increased their anti-inflammatory properties. Interestingly, the HDL from ETC-642 injected mice were also able to reduce the protein levels of the active subunit of NF- $\kappa \mathrm{B}, \mathrm{p} 65$. This reduction in 655 provides a possible mechanism for the reductions in both VCAM-1 and ICAM-1 as they are both regulated via activation of the NF- $\kappa \mathrm{B}$ pathway $[29,30]$. This is also consistent with a number of studies showing that HDL and rHDL reduce NF- $\kappa \mathrm{B}$ activation and the expression of p65 [6,13,31].

The current study demonstrated that infusions of rHDL and ETC-642 inhibit the initial inflammatory response. This suggests that rHDL and ETC-642 may also attenuate the next stages of atherosclerotic lesion development. In support of this, previous work by our group and others has demonstrated that rHDL reduces lesion size and macrophage content in rabbits and mice $[19,32,33]$. Furthermore, adenoviral gene transfer of ETC-642 has been shown to decrease atherosclerosis in apoE $^{-/-}$mice [21].

\section{Conclusions}

Using a cholesterol-fed rabbit model of chronic vascular inflammation we have demonstrated that mimetic peptide ETC-642 inhibits endothelial expression of adhesion molecules, markers of the earliest stages of atherosclerosis. These studies provide additional support for the therapeutic efficacy of mimetic peptides in the treatment of inflammation and cardiovascular disease.

\section{Methods}

Isolation of rabbit HDL and apolipoprotein A-I

Rabbit HDL were isolated from rabbit plasma (100 ml) by sequential ultracentrifugation in the $1.063<\mathrm{d}<1.21$ $\mathrm{g} / \mathrm{ml}$ density range [34] and dialyzed against endotoxinfree phosphate buffered saline (PBS). Human HDL were isolated from pooled samples of autologously donated human plasma (Gribbles Pathology, South Australia) by sequential ultracentrifugation in the same density range. The human HDL were delipidated and apoA-I isolated by anion chromatography [34]. 


\section{Preparation of rHDL containing apoA-I and PLPC}

Discoidal rHDL containing apoA-I complexed to 1-palmitoyl-2-linoleoyl phosphatidylcholine (PLPC) (Avanti Polar Lipids, Alabaster, AL, USA) (initial PLPC/apoA-I molar ratio 100:1). were prepared using the cholate dialysis method [35]. The resulting rHDL were dialysed extensively against endotoxin-free PBS (pH 7.4) before use.

\section{Preparation of ETC-642}

The ETC-642 was provided as a lyophilized solid by Esperion Therapeutics, Pfizer (Groton, MI, USA). The complex consists of ESP-2418, an amphipathic peptide containing 22 L-amino acid residues: P-V-L-D-L-F-R-E-L-L-N-E-L-LE-A-L-K-Q-K-L-K with a molecular weight of 2623 daltons that is complexed to sphingomyelin and 1,2-dipalmitoyl-sn-glycero-3-phosphocholine (DPPC) (peptide/ sphingomyelin/DPPC molar ratio $1 / 3.75 / 3.75$. The lyophilized solid was rehydrated with $50 \mathrm{ml}$ of a sterile bicarbonate saline solution (Esperion Therapeutics, Pfizer, Groton, CT, USA) and gently swirled to mix. Three cycles of warming at $50^{\circ} \mathrm{C}$ and cooling to room temperature were performed to ensure complete reconstitution. The final protein concentration of ETC-642 was $10 \mathrm{mg} / \mathrm{ml}$ and the peptide was stored at $4^{\circ} \mathrm{C}$ until use.

\section{Animal Experiments}

The Sydney South West Area Health Service Animal Welfare Committee approved all animal procedures. Thirty male NZW rabbits weighing approximately $3 \mathrm{~kg}$ were obtained from the Institute of Medical and Veterinary Sciences (Adelaide, South Australia). Following a seven-day acclimatisation period, baseline plasma cholesterol and HDL levels were determined prior to placing the animals on a diet of normal chow supplemented with $0.2 \%(\mathrm{w} / \mathrm{w})$ cholesterol for 6 weeks. Five weeks after commencement of the diet, the rabbits were randomised into three treatment groups ( $\mathrm{n}=10 /$ group). A blood sample $(3 \mathrm{~mL})$ was collected from each animal at this time point. Plasma cholesterol levels were then determined to confirm that there were no significant differences between treatment groups. The animals then received two intravenous infusions of saline (control group), rHDL $(8 \mathrm{mg} / \mathrm{kg}$ apoA-I) or ETC-642 (30 mg/kg peptide) on the third and fifth days of the final (sixth) week of dietary intervention and were sacrificed at the end of the sixth week of high cholesterol feeding. The animals were euthanased with an intravenous overdose of sodium pentobarbital (100 $\mathrm{mg} / \mathrm{kg}$ ). Plasma was collected via cardiac puncture. The thoracic aortae were then removed, flushed with chilled PBS before placement in cold $4 \%(\mathrm{v} / \mathrm{v})$ paraformaldehyde overnight. The aortae were then transferred to $70 \%(\mathrm{v} / \mathrm{v})$ ethanol and stored at $4{ }^{\circ} \mathrm{C}$, then paraffin embedded for histological analysis.

\section{Immunohistochemistry}

Sections $(5 \mathrm{~mm})$ of the paraffin-embedded vessels were cut, dewaxed, and rehydrated. Mouse anti-rabbit VCAM-1 and ICAM-1 antibodies (gifts from Dr M Cybulsky, University of Toronto) were used to assess endothelial expression of adhesion molecules in the thoracic aorta. For the assessment of macrophages, thoracic aortic sections were stained for RAM11 (1:100; Dako). Thoracic aortic sections (10 sections/rabbit) were analysed using ImagePro Plus 4.5 (Media Cybernetics, Silver Spring, MD) as described [3,19]. Image analysis results are expressed as image units.

\section{Plasma Analyses and HDL composition}

Total cholesterol concentrations were determined on rabbit plasma and isolated rabbit HDL enzymatically using commercially available kits (Roche Diagnostics). HDL cholesterol concentrations were determined on rabbit plasma by enzymatic assay following precipitation of apolipoprotein B containing lipoproteins with polyethylene glycol [36]. Phospholipid, unesterified cholesterol, cholesterol ester and triglyceride concentrations were assessed in rabbit HDL also using commercially available kits (Wako Pure Chemicals).

\section{Endothelial cell culture}

Human coronary artery endothelial cells (HCAECs) were grown in MesoEndo cell culture medium (Cell Applications Inc., CA, USA) and seeded at $1 \times 10^{6}$ cells/ well in 12-well plates. Cells were then treated for $24 \mathrm{~h}$ with PBS, rHDL ( $1 \mathrm{mg} / \mathrm{ml}$ final apoA-I concentration) or isolated rabbit HDL $(1 \mathrm{mg} / \mathrm{ml}$ final protein concentration). Following this cells were washed $1 \times$ with PBS and then stimulated with tumor necrosis factor- $\alpha$ (TNF$\alpha)(1 \mathrm{ng} / \mathrm{ml})$. After $5 \mathrm{~h}$ the cells were harvested and stored at $-80^{\circ} \mathrm{C}$ until required.

\section{Real-time PCR}

Total RNA was extracted using the Trizol method, quantitated and normalised to $100 \mathrm{ng} / \mathrm{uL}$ using SYBR Green II assay (Invitrogen). RNA was then reverse transcribed in triplicate to cDNA using iSCRIPT (BioRad). Real-time PCR was performed in triplicate using iQSYBR Green Supermix (BioRad) and an iCycler iQ Real-time thermocycler (BioRad). The threshold cycle was calculated using iCycler iQ Real-time PCR detection system software version 3.0A (BioRad). Relative changes in mRNA expression between treatments were determined using the cT method. Results were normalised using GAPDH.

\section{Statistical Analyses}

All results are expressed as mean \pm SEM. Statistical comparisons were made by two-tailed Student's t-tests 
and one way ANOVA with Bonferroni's test post hoc using GraphPad Prism Version 4.0 (San Diego, CA). A value of $\mathrm{p}<0.05$ was considered statistically significant.

\author{
Abbreviations \\ (apoA-I): Apolipoprotein A-I; (apoE): Apolipoprotein E, (DPPC): 1,2-dipalmitoyl- \\ sn-glycero-3-phosphocholine, (GAPDH): Glyceraldehyde 3-phosphate \\ dehydrogenase, (HDL): High-density lipoproteins, (HCAECs): Human coronary \\ artery endothelial cells, (ICAM-1): Intracellular cell adhesion molecule-1, \\ (mRNA): Messenger ribonucleic acid, NZW rabbits: New Zealand White \\ rabbits, (NF-kB): Nuclear factor kappa-light-chain-enhancer of activated B \\ cells, (p65): p65 subunit of NF-KB, (PLPC): 1-palmitoyl-2-linoleoyl \\ phosphatidylcholine, (PBS): Phosphate buffered saline, (rHDL): Reconstituted \\ HDL, (TNF-a): Tumour necrosis factor-a; (VCAM-1): Vascular cell adhesion \\ molecule-1.
}

\section{Acknowledgements}

This study was supported by a Heart Research Institute PhD scholarship (Dr Di Bartolo) and a Heart Foundation Career Development Fellowship (Dr Bursill) (CR07S3331).

\section{Author details}

'Lipid Research Group, Heart Research Institute, 7 Eliza St, Newtown, NSW, 2042, Australia. Immunobiology Unit, Heart Research Institute, 7 Eliza St, Newtown, NSW, 2042, Australia. ${ }^{3}$ Discipline of Pathology, University of Sydney, Camperdown, NSW, 2050, Australia. ${ }^{4}$ Department of Medicine, University of Sydney, Camperdown, NSW, 2050, Australia. ${ }^{5}$ Department of Medicine, University of Melbourne, Parkville, Victoria, 3010, Australia.

\section{Authors' contributions}

BAD-Performed in vivo and in vitro studies as well as the histology. Also assisted in the preparation of the manuscript. LZV-Performed quantitative PCR experiments. JTMT-Assisted in in vitro studies and quantitative PCR experiments. SB-Performed analysis of histological sections. KAR-Conceived the project and experimental design and assisted in the preparation of the manuscript. PJB-Conceived the project and assisted in the preparation of the manuscript. CAB-Assisted with the experiments and prepared the manuscript. All authors have read and approved the manuscript.

\section{Competing interests}

The authors declare that they have no competing interests.

Received: 26 August 2011 Accepted: 30 November 2011 Published: 30 November 2011

\section{References}

1. Libby P: Inflammation in atherosclerosis. Nature 2002, 420:868-874.

2. Barter PJ, Nicholls S, Rye KA, Anantharamaiah GM, Navab M, Fogelman AM: Antiinflammatory properties of HDL. Circ Res 2004, 95:764-772.

3. Nicholls SJ, Dusting GJ, Cutri B, Bao S, Drummond GR, Rye KA, Barter PJ: Reconstituted high-density lipoproteins inhibit the acute pro-oxidant and proinflammatory vascular changes induced by a periarterial collar in normocholesterolemic rabbits. Circulation 2005, 111:1543-1550.

4. Clay MA, Pyle DH, Rye KA, Vadas MA, Gamble JR, Barter PJ: Time sequence of the inhibition of endothelial adhesion molecule expression by reconstituted high density lipoproteins. Atherosclerosis 2001, 157:23-29.

5. Cockerill GW, Rye KA, Gamble JR, Vadas MA, Barter PJ: High-density lipoproteins inhibit cytokine-induced expression of endothelial cell adhesion molecules. Arterioscler Thromb Vasc Biol 1995, 15:1987-1994.

6. Bursill CA, Castro ML, Beattie DT, Nakhla S, van der Vorst E, Heather AK, Barter PJ, Rye KA: High-density lipoproteins suppress chemokines and chemokine receptors in vitro and in vivo. Arterioscler Thromb Vasc Biol 30:1773-1778.

7. Dimayuga P, Zhu J, Oguchi S, Chyu KY, Xu XO, Yano J, Shah PK, Nilsson J, Cercek B: Reconstituted HDL containing human apolipoprotein A-1 reduces VCAM-1 expression and neointima formation following periadventitial cuff-induced carotid injury in apoE null mice. Biochem Biophys Res Commun 1999, 264:465-468
8. Puranik R, Bao S, Nobecourt E, Nicholls SJ, Dusting GJ, Barter PJ, Celermajer DS, Rye KA: Low dose apolipoprotein A-I rescues carotid arteries from inflammation in vivo. Atherosclerosis 2008, 196:240-247.

9. Ou Z, Ou J, Ackerman AW, Oldham KT, Pritchard KA Jr: L-4F, an apolipoprotein A-1 mimetic, restores nitric oxide and superoxide anion balance in low-density lipoprotein-treated endothelial cells. Circulation 2003, 107:1520-1524.

10. Garber DW, Datta G, Chaddha M, Palgunachari MN, Hama SY, Navab M, Fogelman AM, Segrest JP, Anantharamaiah GM: A new synthetic class A amphipathic peptide analogue protects mice from diet-induced atherosclerosis. J Lipid Res 2001, 42:545-552.

11. Navab M, Anantharamaiah GM, Hama S, Garber DW, Chaddha M, Hough G, Lallone R, Fogelman AM: Oral administration of an Apo A-I mimetic Peptide synthesized from $D$-amino acids dramatically reduces atherosclerosis in mice independent of plasma cholesterol. Circulation 2002, 105:290-292.

12. Ou J, Wang J, Xu H, Ou Z, Sorci-Thomas MG, Jones DW, Signorino P, Densmore JC, Kaul S, Oldham KT, Pritchard KA Jr: Effects of D-4F on vasodilation and vessel wall thickness in hypercholesterolemic LDL receptor-null and LDL receptor/apolipoprotein A-I double-knockout mice on Western diet. Circ Res 2005, 97:1190-1197.

13. Tabet F, Remaley AT, Segaliny Al, Millet J, Yan L, Nakhla S, Barter PJ, Rye KA, Lambert G: The 5A apolipoprotein A-I mimetic peptide displays antiinflammatory and antioxidant properties in vivo and in vitro. Arterioscler Thromb Vasc Biol 30:246-252.

14. Blackburn WDDJ Jr, Venkatachalapathi YV, Pillion DJ, Koopman WJ, Segrest JP, Anantharamaiah GM: Apolipoprotein A-I decreases neutrophil degranulation and superoxide production. J Lipid Res 1991, 32:1911-1918.

15. Anantharamaiah GMVY, Brouillette CG, Segrest JP: Use of synthetic peptide analogues to localize lecithin:cholesterol acyltransferase activating domain in apolipoprotein A-I. Arteriosclerosis 1990, 10:95-105.

16. Di Bartolo BA, Nicholls SJ, Bao S, Rye KA, Heather AK, Barter PJ, Bursill C: The apolipoprotein A-I mimetic peptide ETC-642 exhibits antiinflammatory properties that are comparable to high density lipoproteins. Atherosclerosis .

17. Finking G, Hanke H: Nikolaj Nikolajewitsch Anitschkow (1885-1964) established the cholesterol-fed rabbit as a model for atherosclerosis research. Atherosclerosis 1997, 135:1-7.

18. Li H, Cybulsky Ml, Gimbrone MA Jr, Libby P: An atherogenic diet rapidly induces VCAM-1, a cytokine-regulatable mononuclear leukocyte adhesion molecule, in rabbit aortic endothelium. Arterioscler Thromb 1993, 13:197-204.

19. Nicholls SJ, Cutri B, Worthley SG, Kee P, Rye KA, Bao S, Barter PJ: Impact of short-term administration of high-density lipoproteins and atorvastatin on atherosclerosis in rabbits. Arterioscler Thromb Vasc Biol 2005, 25:2416-2421.

20. Busseuil D, Shi Y, Mecteau M, Brand G, Kernaleguen AE, Thorin E, Latour JG, Rheaume E, Tardif JC: Regression of aortic valve stenosis by ApoA-I mimetic peptide infusions in rabbits. Br J Pharmacol 2008, 154:765-773.

21. Bodary PFSY, Westrick RJ, Lalwani ND, Drake SL, Dasseux JLH: Gene Transfer of an ApoA-I mimetic peptide reduces atherosclerosis in mice. $J$ Am Coll Cardiol 2004, 43(Suppl 2):A465-A466.

22. Rothblat GH, Phillips MC: High-density lipoprotein heterogeneity and function in reverse cholesterol transport. Curr Opin Lipidol 21:229-238.

23. Besler C, Heinrich K, Riwanto M, Luscher TF, Landmesser U: High-density lipoprotein-mediated anti-atherosclerotic and endothelial-protective effects: a potential novel therapeutic target in cardiovascular disease. Curr Pharm Des 16:1480-1493.

24. Navab M, Anantharamaiah GM, Reddy ST, Hama S, Hough G, Grijalva VR, Yu N, Ansell BJ, Datta G, Garber DW, Fogelman AM: Apolipoprotein A-I mimetic peptides. Arterioscler Thromb Vasc Biol 2005, 25:1325-1331.

25. Khan MLN, Drake SL, Crockatt JG, Dasseux JLH: Single-dose intravenous infusion of ETC-642, a 22-Mer ApoA-I analogue and phospholipids complex, elevates HDL-C in atherosclerosis patients. Circulation 2003, 108(Suppl IV):563-564.

26. Patel S, Di Bartolo BA, Nakhla S, Heather AK, Mitchell TW, Jessup W, Celermajer DS, Barter PJ, Rye KA: Anti-inflammatory effects of apolipoprotein A-I in the rabbit. Atherosclerosis 212:392-397.

27. Gordon SM, Deng J, Lu LJ, Davidson WS: Proteomic characterization of human plasma high density lipoprotein fractionated by gel filtration chromatography. J Proteome Res 9:5239-5249. 
28. Davidson WS, Silva RA, Chantepie S, Lagor WR, Chapman MJ, Kontush A: Proteomic analysis of defined HDL subpopulations reveals particlespecific protein clusters: relevance to antioxidative function. Arterioscler Thromb Vasc Biol 2009, 29:870-876.

29. Hadad N, Tuval L, Elgazar-Carmom V, Levy R: Endothelial ICAM-1 protein induction is regulated by cytosolic phospholipase A2alpha via both NFkappaB and CREB transcription factors. J Immunol 186:1816-1827.

30. Ju J, Naura AS, Errami Y, Zerfaoui M, Kim H, Kim JG, Abd Elmageed ZY, Abdel-Mageed AB, Giardina C, Beg AA, Smulson ME, Boulares AH: Phosphorylation of p50 NF-kappaB at a single serine residue by DNAdependent protein kinase is critical for VCAM-1 expression upon TNF treatment. J Biol Chem 285:41152-41160.

31. MCGrath KC, Li XH, Puranik R, Liong EC, Tan JT, Dy VM, DiBartolo BA, Barter PJ, Rye KA, Heather AK: Role of 3beta-hydroxysteroid-delta 24 reductase in mediating antiinflammatory effects of high-density lipoproteins in endothelial cells. Arterioscler Thromb Vasc Biol 2009, 29:877-882.

32. Choudhury RP, Rong JX, Trogan E, Elmalem VI, Dansky HM, Breslow IL, Witztum $J L$, Fallon JT, Fisher EA: High-density lipoproteins retard the progression of atherosclerosis and favorably remodel lesions without suppressing indices of inflammation or oxidation. Arterioscler Thromb Vasc Biol 2004, 24:1904-1909.

33. Rong JX, Li J, Reis ED, Choudhury RP, Dansky HM, Elmalem VI, Fallon JT, Breslow JL, Fisher EA: Elevating high-density lipoprotein cholesterol in apolipoprotein E-deficient mice remodels advanced atherosclerotic lesions by decreasing macrophage and increasing smooth muscle cell content. Circulation 2001, 104:2447-2452.

34. Rye KA, Garrety KH, Barter PJ: Preparation and characterization of spheroidal, reconstituted high-density lipoproteins with apolipoprotein A-I only or with apolipoprotein A-I and A-II. Biochim Biophys Acta 1993, 1167:316-325.

35. Matz CE, Jonas A: Micellar complexes of human apolipoprotein A-I with phosphatidylcholines and cholesterol prepared from cholate-lipid dispersions. J Biol Chem 1982, 257:4535-4540.

36. Allen JK, Hensley WJ, Nicholls AV, Whitfield JB: An enzymic and centrifugal method for estimating high-density lipoprotein cholesterol. Clin Chem 1979, 25:325-327.

doi:10.1186/1476-511X-10-224

Cite this article as: Di Bartolo et al:: The apolipoprotein A-I mimetic peptide, ETC-642, reduces chronic vascular inflammation in the rabbit. Lipids in Health and Disease 2011 10:224.

\section{Submit your next manuscript to BioMed Central and take full advantage of:}

- Convenient online submission

- Thorough peer review

- No space constraints or color figure charges

- Immediate publication on acceptance

- Inclusion in PubMed, CAS, Scopus and Google Scholar

- Research which is freely available for redistribution

Submit your manuscript at www.biomedcentral.com/submit
CioMed Central 